Studia Anglica Posnaniensia 51/1, 2016

doi: 10.1515/stap-2016-0002

\title{
A CONSTRUCTIONAL ANALYSIS OF OBLIGATORY XVS SYNTACTIC STRUCTURES ${ }^{\dagger}$
}

\author{
CARLOS PRADO-ALONSO*
}

University of Oviedo

\begin{abstract}
The analysis of obligatory or formulaic XVS structures — as in "Here comes the sun" or "Now is the time to solve our problems" - has been neglected in the literature since it has been argued that there seems to be no linguistic variation involved in the use of these types of syntactic constructions. Here, I defend the view that obligatory XVS structures are productive, highly structured constructions which are worthy of serious linguistic investigation. On the basis of a corpus-based analysis of written and spoken texts, it is argued that the different obligatory XVS types distinguished in the literature are clear instances of constructions as understood in the Construction Grammar framework. Despite their formal and functional dissimilarities, the article shows that these XVS structures still relate to one another in systematic and predictable ways, and are in fact grouped in relation to a unit in the schematic network which is naturally most salient — the prototype - and form with it a family of nodes which are extensions from the prototype - in the system. In sum, the analysis here will show that obligatory XVS structures are constructions which form an interconnected, structured system or network and are best understood with reference to different forms of inheritance.
\end{abstract}

Keywords: word-order, XVS constructions, radial, prototype, corpus linguistics

\section{Introduction}

Over the past few decades, XVS constructions in which the subject follows the entire verb phrase in a declarative clause - as in "On the near corner was

$\dagger \quad$ I am grateful to the Spanish Ministry of Economy and Competitiveness for generous financial support (National Programme for Excellence in Scientific and Technical Research; grant FFI2014-52188-P).

* Corresponding author: Carlos Prado-Alonso, pradocarlos@uniovi.es, Department of English, French and German, Faculty of Philosophy and Letters, University of Oviedo, Campus de El Milán, C/ Teniente Alfonso Martínez s/n, E-33011 Oviedo, SPAIN 
Herb's Gas Station" or "Upstairs was a bedroom and a bathroom" - have been the subject of extensive research (Bresnan and Kanerva 1992; Schachter 1992; Birner 1996; Dorgeloh 1997; Chen 2003; Kreyer 2006; Prado-Alonso 2008, 2011, Webelhuth 2014), the focus of each individual study varying according to the nature and goals of the specific theoretical framework adopted.

Most studies on English XVS constructions base their classifications on the preliminary distinction between two main types of XVS constructions: nonobligatory XVS and formulaic or obligatory XVS constructions. Nonobligatory XVS constructions are constructions in which the addressor can opt for either the inverted word-order or its canonical SVX counterpart (1) ${ }^{1}$.

By contrast, obligatory XVS constructions are obligatorily triggered by certain fixed preverbal constituents, and are not replaceable in context by a comparable clause with SVX canonical word-order because this is grammatically unavailable or conveys a different meaning, as illustrated in (2)-(3) ${ }^{2}$.

1) a. On his right was the mountain. XVS

b. The mountain was on his right. SXV

2) a. Here comes an opportunity for the health services.

b. An opportunity for the health services comes here.

3) a. Here is our correspondent Mark Tully.

b. Our correspondent Mark Tully is here.

The analysis of obligatory or formulaic XVS constructions has been neglected in the literature, with most studies focussing only on the non-obligatory type (Kreyer 2006, among others), since it has been argued (Green 1982; Chen 2003) that there seems to be no linguistic variation involved in the use of these types of constructions. Here, I defend the view that obligatory XVS structures are

1 Unless otherwise stated, the different obligatory XVS instances have been retrieved from written and spoken computerised corpora, namely the Freiburg-Lancaster-Oslo-Bergen Corpus of British English (FLOB), the Freiburg-Brown Corpus of American English (FROWN), the British English 2006 Corpus (BrE06), the American English 2006 Corpus (AmE06), the International Corpus of English: the British Component (ICE-GB) and the Corpus of Spoken Professional American English (CSPAE). For details on the corpora, see Section 3.1.

2 I am aware that there is not a complete agreement in the literature as to the status of the preverbal constituents in these types of structures. On the one hand, a number of studies (Lakoff 1987, Bresnan and Kanerva 1992, among others) view the locative adverb in examples such as (2-3) as the expletive subject, while the postverbal constituent is considered a predicate nominal. On the other hand, other studies (Birner 1996, Dorgeloh 1997, Chen 2003 , or Kreyer 2006, among others) view the postverbal constituent as the subject. Here I side with those who consider the postverbal constituent as the subject. Several syntactic criteria, such as the fact that it is the postverbal element that normally controls the agreement with the verb, make it clear that, despite their controversial character, it is possible to analyse these types of examples as XVS structures. 
productive, highly structured constructions which are worthy of serious linguistic investigation. On the basis of a statistical analysis based on corpora of Present-day written and spoken English, I will argue that the different obligatory XVS types distinguished in the literature are clear instances of constructions as understood in the Construction Grammar framework (Goldberg 1995). Despite their formal and functional dissimilarities, these inversions still relate to one another in systematic and predictable ways and I will show that in fact the inversions are grouped in relation to a unit in the schematic network which is naturally most salient — the prototype (Langacker 1987: 492) — and form with it a family of nodes - extensions from the prototype (Langacker 1991: 548) in the system. In sum, the analysis here will show that obligatory XVS structures are constructions, namely form-meaning correspondences which in themselves carry meaning, independently of the words in the sentence (Langacker 1987: Ch. 2). It will also be shown that these constructions form an interconnected, structured system or network and are best understood with reference to different forms of inheritance (Goldberg 1995: 72 ff).

Section 2 offers some preliminaries, including a definition of the XVS structures analysed here and a brief description of the non-obligatory and obligatory uses of these constructions. Section 3 provides the results for the types and distribution of obligatory XVS structures in a corpus-based analysis of written and spoken English texts. Section 4 discusses evidence for the existence of obligatory XVS structures as constructions. Section 5 offers a constructional analysis of XVS structures. Finally, Section 6 offers some concluding remarks.

2. XVS structures: non-obligatory and obligatory uses

XVS structures occur in those declarative clauses where the grammatical subject follows the entire verb phrase, that is, when "the subject occurs in postposed position while some other dependent of the verb is preposed" (Huddleston and Pullum 2002: 1385), as illustrated in (4).

4) On the mantel is a clock with its time stopped at 12:43.

5) Beyond were the huge ranches and a smattering of stately southern homes.

6) An example is the Malaysian government's enormous land development programme.

7) Equally significant was the trading volume on the New York Stock Exchange.

8) Gone was her singing and her warm smile.

On the basis of the kind of phrasal category occurring as a preverbal constituent, five different types of XVS structures have traditionally been distinguished in the 
literature: prepositional phrase, adverb phrase, noun phrase, adjective phrase and verb phrase XVS structures, as illustrated in (4)-(8) respectively. However, as Dorgeloh (1997: 97) notes, on many occasions opting between the XVS structure and its SVX canonical counterpart is not a choice available to the addressor, either because the non-inverted version is grammatically impossible or because it would convey a different meaning (cf. 2 and 3). For this reason the different types of XVS structures (PP, VP, NP, etc.) have been further grouped into two main categories: non-obligatory and obligatory XVS structures. Non-obligatory XVS structures are exemplified in (4)-(8) above, where the canonical SVX counterpart is also available to the addressor. Obligatory XVS structures are formulaic structures which are triggered, among others, by deictic adverbs (9a), enumerative listing conjuncts (10a), anaphoric or additive forms (11a), and where the canonical SVX version is either not grammatical or conveys a different meaning (cf. 9b-11b).

9) a. Then was the red brick library with the twin lion statues flanking the double doors.

b. *The red brick library with the twin lion statues flanking the double door was then.

10) a. First, in 1986, came the departure of ACT founder William Ball, who left under what may be charitably called a cloud. Then came the 1989 earthquake.

b. ? The departure of ACT found William Ball, who left under that may be charitably called a cloud, came first, in 1986. The 1989 earthquake came then.

11) a. Transoceanic commerce is one of these inter-relationships. The common heritage of science is another and so is the aspiration to add to it.

b. *Transoceanic commerce is one of these inter-relationships. The common heritage of science is another and the aspiration to add to it is so.

What follows provides a discussion of the specific types of obligatory XVS structures retrieved from the analysis of different written and spoken English corpora. The analysis also provides the distributional patterns of these XVS structures, which is the basis for the constructional analysis provided in Section 5.

3. Obligatory XVS structures in written and spoken Present-day English texts

\subsection{The corpora}

To analyse the behaviour and distribution of obligatory XVS structures in written and spoken English, six computerised corpora have been selected. For written English, these are: 
(i) the Freiburg-Lancaster-Oslo-Bergen Corpus of British English (FLOB; compilation date: 1991)

(ii) the Freiburg-Brown Corpus of American English (FROWN; compilation date: 1992)

(iii) the British English 2006 Corpus (BrE06)

(iv) the American English 2006 Corpus (AmE06); for details see Hofland et al. (1999) and Baker (2009).

For spoken English, I used the spoken section of

(i) the International Corpus of English: the British Component (ICE-GB; compilation date: 1990-1993)

(ii) the Corpus of Spoken Professional American English (CSPAE; compilation date: 1994-1998); for details see Nelson (1998) and Barlow (2000).

The written corpora comprise 2.000 samples of approximately 2,000 words each, thus totalling 4,000,000 running words organised into fifteen textual categories, of which the following eight have been selected for the present analysis:

(i) Science Fiction

(ii) Adventure and Western

(iii) Mystery and Detective Fiction

(iv) Romance and Love Story

(v) General Fiction

(vi) Academic Prose

(vii) Press Reportage

(viii) Official Documents ${ }^{3}$

These categories have been further grouped into fictional and non-fictional texts. A total sample of $2,169,000$ words will be analysed, distributed as indicated in Table 1 below.

The spoken material analysed in ICE-GB contains:
(i) Public Dialogues of Classroom Lessons
(ii) Broadcast Discussions
(iii) Broadcast Interviews
(iv) Parliamentary Debates
(v) Legal Cross-examinations
(vi) Business Transactions

3 The Official Documents textual category comprises government documents, institutional reports, industry reports, college catalogues and in-house industry texts. 
(vii) Scripted monologues

a) Broadcast news

b) Broadcast talks

c) Non-broadcast talks

(viii) Unscripted monologues
a) Unscripted speech
b) Demonstrations
c) Legal presentations

As shown in Table 2, the CSPAE compilation, in turn, consists of samples taken from Conference Meetings held around the United States, Transcripts of White House Conferences, and Faculty meetings at the University of North Carolina, which include questions, interactions and involve statements and discussions of political and academic issues. A total sample of 2,169,000 words will be analysed, distributed as indicated in Table 2 on page 57.

Table 1. Sources and distribution of the corpus texts selected from FLOB, FROWN, BrE06, and AmE06.

\begin{tabular}{lrlr}
\hline \multicolumn{2}{c}{ Fictional textual categories } & \multicolumn{1}{c}{ Non-fictional textual categories } \\
\hline \multicolumn{1}{c}{ texts } & \multicolumn{1}{c}{ words } & \multicolumn{1}{c}{ texts } & words \\
\hline Science Fiction & 48,000 & Academic Prose & 640,000 \\
Adventure and Western & 232,000 & Press Reportage & 252,000 \\
Mystery and Detective & 192,000 & Official Documents & 240,000 \\
Romance and Love Story & 232,000 & & \\
General Fiction & 232,000 & & $1,232,000$ \\
SUBTOTAL & 937,000 & & \\
\hline TOTAL & & $2,169,000$ words & \\
\hline
\end{tabular}

Since the textual categories of written and spoken English differ in size, frequencies have been normalised following Biber's (1988: 14) proposal for a "normalised frequency of a feature". As Biber notes, "raw frequency counts cannot be used for comparison across texts when they are not at all of the same length", since in this case longer texts would tend to have higher frequencies simply because there is more opportunity for a feature to occur within them. Using Biber's procedure and comparing the frequency per 100;1,000;10,000, or 100,000 words - depending on the frequency of the feature under investigation - this possible bias is eliminated. In the present study, given that obligatory XVS structures are considered relatively rare syntactic constructions compared to unmarked SVX word-order (Biber et al. 1999: 926), normalised frequencies are computed by dividing absolute frequencies by the total number of words of each category. The result is then multiplied by 100,000 . 


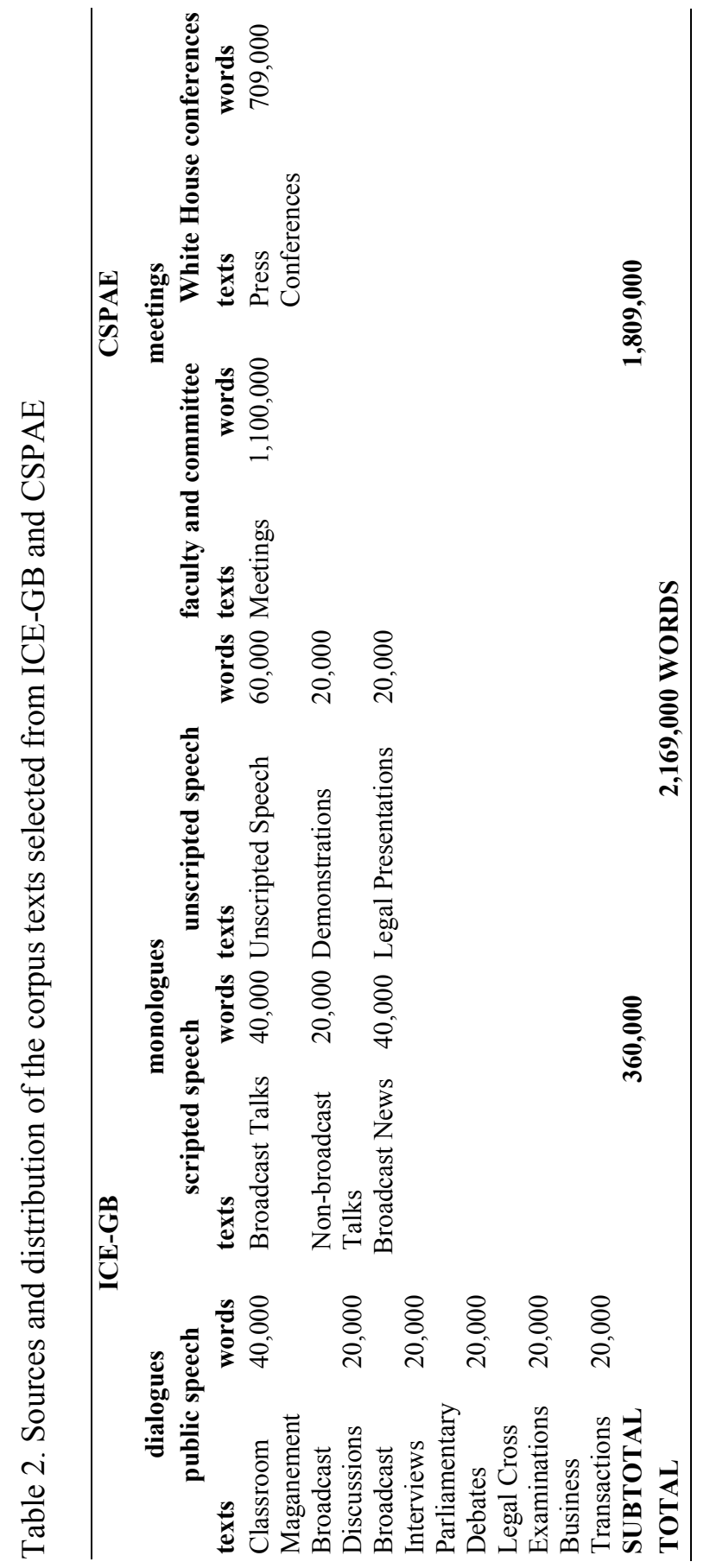




\subsection{Obligatory XVS structures in writing and speech}

The analysis of the written and spoken corpora has yielded 631 instances of obligatory XVS structures. On the basis of the corpora, the instances can be grouped into three main types:

(i) obligatory XVS structures triggered by deictic adverbs,

(ii) obligatory XVS structures triggered by enumerative listing conjuncts

(iii) obligatory XVS structures triggered by anaphoric or additive adverbs.

Obligatory XVS structures triggered by deictic adverbs such as here, now, there, then are fairly idiomatic constructions because there is a sharp difference in meaning between the XVS construction and its canonical SVX counterpart (cf. 12-13).

12) a. Here comes the best player of all times.

b. The best player of all times comes here.

13) a. Here are the Prophet Elias, the Emperor of the Universe, the Universal Empress, he Empress of Turkey, the only daughter of God Almighty, Queen Elizabeth (...)

b. The Prophet Elias, the Emperor of the Universe, the Universal Empress, the Empress of Turkey, the only daughter of God Almighty, Queen Elizabeth (...) are here.

Examples such as (12a), for instance, have traditionally been regarded as instantiations of a particular routine in spoken language; as argued by Huddleston and Pullum (2002: 1390) they "are comparable to running commentaries, describing a situation that takes place or is taking place as they are uttered". This is clearly reflected in the temporal meaning of the deictic element -here- in this example: Here/Now comes the best player of all times. Such a temporal meaning is not found in the canonical SVX variant in $12 \mathrm{~b}$, where the deictic element can only be interpreted as locative.

A similar formulaic presentative function of obligatory XVS constructions is also seen in (13), in which the canonical word-order, though possible, conveys a different meaning. In (13a), deictic here is used as a presentative device to introduce new information in discourse and defines the entities referred to by the postposed subject as being close to the addressor's location. The unmarked version in (13b) cannot be felicitously used in this way (see Section 5).

The second type of obligatory XVS structures attested in the corpora occurs when the preverbal trigger is an enumerative listing conjunct (Quirk et al. 1985: 
635; Biber et al. 1999: 875), as illustrated in (10) repeated here for convenience. Linking adverbials of this kind, which include ordinal numbers, first, second, third, etc. (cf. 14), and adverbs such as finally or lastly, can be used for the enumeration of pieces of information in an order chosen by the addressor, and perform a linking function.

10) a. First, in 1986, came the departure of ACT founder William Ball, who left under what may be charitably called a cloud. Then came the 1989 earthquake.

b. ? The departure of ACT found William Ball, who left under that may be charitably called a cloud, came first, in 1986. The 1989 earthquake came then.

14) Fifth is the question mark over the real level of support for the Government.

The canonical variants of (10) and (14) differ in meaning from their XVS counterparts and cannot be used in the same linguistic context. In (10a), for instance, preverbal first and then are adverbial pointers which help to indicate the progression of events and mark the successive stages in discourse. In other words, they order the level of discourse metalinguistically. This is not the case in (10b), which is why the SVX clause is grammatically acceptable but infelicitous. Here the clause-final then simply conveys a temporal meaning and denotes that the action takes place at the moment indicated by the addressor, but does not perform a sequential cohesive function.

The third type of obligatory XVS structure attested in the corpora occurs when the preverbal trigger is an anaphoric or additive adverb as illustrated in (15)-(16).

15) a. He is open for student suggestions or questions and so is Margaret Phillips, area coordinator for Neptune and Gilbert Halls.

b. *He is open for student suggestions or questions and Margaret Phillips, area coordinator for Neptune and Gilbert Halls, is so.

16) Major changes in either markets or policy are unlikely in the short run. Neither is any set of partial reforms likely to 'solve the poverty problem.

In (15) the initial so stands for given information, and has a cohesive effect. Furthermore, its location in preverbal position emphasises the parallelism between both clauses. The subject, which is the main communicative focus, is 
placed in end position, in accordance with the principles of Communicative Dynamism and End-focus (Hartvigson and Jakobsen 1974: 62). As noted by Biber et al. (1999: 916), this XVS pattern expressing a parallelism can be considered obligatory because there is no completely equivalent canonical wordorder; it can merely be paraphrased with subject-verb order plus additive too, i.e. Margaret Phillips is so too. Similarly in (16) the clause initial constituent in the XVS construction expresses a parallelism with the preceding negative clause. The construction can be paraphrased with a subject-verb order clause containing or or either, but there is no exact canonical variant.

As illustrated in Table 3 next page, the data show that obligatory XVS structures take place more frequently in speech (429 instances; normalised frequency: 19.7) than in writing (202 instances: normalised frequency: 9.3). Beyond this, as will be shown presently, these two genres differ significantly in their use of the different types of XVS structures in the textual categories and in the specific items which trigger the constructions.

The results show that the obligatory XVS structure triggered by deictic adverbs such as here, there, now and then (496 tokens) is the prototypical type of obligatory XVS structure in English. The other types of obligatory XVS structures, namely inverted structures triggered by enumerative listing conjuncts (77 tokens) and by anaphoric or additive such as so, neither, or nor (58 tokens) are found more rarely.

Obligatory XVS constructions triggered by deictic here, there, now and then have been far more frequently attested in speech (388 instances/normalised frequency: 17.9), than in writing (108 instances/normalised frequency: 5). As Chafe (1994) notes, one of the basic properties which sets speaking and writing apart is the notion of situatedness. This notion has to do with "the closeness language has to the immediate physical and social situation in which it is produced and received" (Chafe 1994: 44). From this it follows that two important situational properties distinguish writing from speaking: (1) whether the producer and receivers of the message are co-present, and (2) whether they interact. Conversational language typically involves participants who share the same location in space and time, and who alternate in their roles. Writing is different in both respects. Typically writer and reader occupy different locations, and they rarely interact. With this difference in mind, Green (1982: 130) argues that obligatory XVS structures triggered by here, there, now and then are typical oral-language constructions because their use is subject to the restriction that there must be an interaction between addressor and addressee in the communicative event. The analysis of the written corpora, however, shows that the use of obligatory XVS structures triggered by here, there, now and then may also be attested in written discourse, though more restrictedly. This occurs because the deictic reference conveyed through these constructions can also be made to the text itself. 
In other words, a text creates its own deictic dimensions and offers an alternative perceptual field which is available to the writer and the reader, and where direct speech contexts with a conversational status may also be present. This is especially noticed if we compare the distribution of this type of obligatory XVS structure in the fictional and non-fictional texts of the written corpora: frequency of occurrence is consistently higher in the fictional categories with General Fiction (10.3) and Romance and Love Story (8.6) showing the highest frequencies (cf. Table 3). As pointed out in Biber et al. (1999: 795), "conversation and to a lesser extent fiction have especially high frequencies of the adverbs just (in restrictive, not time, sense), now, then, here, and there". What is more, in fiction, the use of here, there, now, and then is similar to conversation "though referring to the fictional world of the text rather than the real world" (ibid: 799). Conversational features may then also be natural in writing when the addressor writes as if he or she were speaking, or wants to reflect direct speech situations. In (17), for instance, the XVS construction here is your cash is presented through the words of a character - the rabbi - who addresses another participant in the events.

17) "You have my word, nothing will go wrong."

"Yes, but suppose something unforeseen did," Albert insisted, "Would you return the cash?"

"Here is your cash," said the rabbi, handing the teacher the packet of folded bills.

By contrast, the non-fictional texts are characterised by a lower frequency of "conversational contexts", and thus fewer obligatory XVS structures triggered by here, there, now and then are found (see Table 3). This is specially the case of Academic Prose (four instances/normalised frequency: 0.6), whose texts hardly include interactions or direct speech clauses. Press Reportage (18 instances/normalised frequency: 5.1) and Official Documents (12 instances/normalised frequency: 5) show a higher incidence of this type of obligatory XVS structures than Academic Prose because they are more conversationally oriented. In press reports, as argued by Biber (1988: 191), there is a presence of news analyses but also of narrative text portions, that is, description of features, acts or events in which direct speech clauses and references to the implied reader are common. Official Documents comprises some texts which have been written to be read aloud and obligatory XVS structures triggered by here, there, now and then are found in contexts where the addressor directly addresses the addressee in the text or in questions.

As shown in Table 3, obligatory XVS structures triggered by enumerative listing conjuncts have been more frequently attested in writing (50 instances/normalised frequency: 2.3 ) than in speech (27 instances/normalised frequency: 1.2). The construction has been most frequently attested in academic prose texts 
(42 instances/normalised frequency: 6.5). As Biber et al. (1999: 880) note linking adverbials are considerably more common in academic prose than in speech, and academic prose uses enumerative adverbials more than other registers. It is widely accepted (Biber et al. 1999, Huddleston and Pullum 2002, among others) that an important aspect of academic prose is the presentation of expository information. However, academic writing is also concerned with the development of arguments, and obligatory XVS structures triggered by linking adverbials are commonly used for this purpose, as shown in (18) below. In this example, the different obligatory XVS structures allow the addressor to give a detailed, concise, and temporally structured explanation about the topic of the texts, namely the division of American social classes. The XVS structures mark the links between ideas overtly and help the addressee to better understand the sequence of facts, since he or she is guided temporally in each step of the discussion, and can easily note the most important statements of the message. Because they explicitly signal the connections between passages, XVS structures triggered by linking adverbials are important devices for creating textual cohesion and signalling the macrostructural sectioning of the text in academic discourse.

18) For purposes of analysis, it is often helpful to divide American society into five social classes. First is a very small upper class, or social elite, consisting chiefly of those who have inherited social privilege from others. Second is a larger upper middle class, whose members often are professionals, corporate managers, leading scientists, and the like. (...) The third (or middle) social class has been called the lower middle class. (...) Fourth in the hierarchy of social class is the working class, whose member are largely blue-collar workers (industrial wage earners), or employees in low-paid service occupations. (...) Finally, fifth in the hierarchy is the lower class.

Obligatory XVS structures triggered by anaphoric or additive adverbs such so, neither, and nor have been hardly attested in the spoken corpora (14 instances/normalised frequency: 0.6 ) and have been found more frequently in the written corpora (44 instances/normalised frequency: 2). These constructions perform a clause-linking function of referents in discourse in which the information presented in the superordinate clause is also applied to the subordinate clause, as shown in (19).

19) Conservative efforts in 1990 to temper the effects of the poll tax and to slow down the implementation of NHS reform are evidence for the robustness of the Downsian median. $\underline{\text { So }}$ are the strenuous efforts of Neil Kinnock to lead the Labour Party to it. 
An explanation for the more frequent use of these types of obligatory XVS structures in writing than in speech is that the written mode generally needs more cohesive constructions than the spoken mode because, as noted by Chafe (1992), it takes place most commonly under conditions of displacement, that is, it deals with events which are not part of the immediate environment of addressor or addressee. Formal cohesion must be tighter because the situational context is not there to fill in any possible gaps. By contrast, the spoken language tends to have a more fragmented character and, due also to the speed needed to code messages, it exhibits a far less structured syntax than the written language. As Chafe (1992: 38) notes, and as is well-known, speech often strings together connected clauses even without connectives themselves because the connections are 'in the air' and, if misunderstood, can be rapidly repaired anyway. Of course people sometimes plan what they want to say in conversations, but even in such cases syntax is not likely to be as elaborated as in writing (Chafe 1992). Thus the speaker typically repeats himself a good deal, uses similar syntactic structures, similar lexical items, the first word that comes to mind rather than hunting for the most accurate one, etc. This is not the case in writing where, as we jot down one idea, our thoughts have plenty of time to move ahead to others. The result is that we have time to integrate a succession of ideas into a more complex, coherent, and integrated whole, making use of cohesive devices such as obligatory XVS structures with enumerative listing conjuncts, and with preverbal anaphoric or additive adverbs. In speech the relationship between ideas is encoded by means other than these obligatory XVS structures (pitch, prominence, pauses, and changes in tempo and voice quality, as well as gestures). Orientation or anchoring tasks, topic changes, prominence of individual constituents, expressions of emotions, can thus be performed using these sources of information in parallel with the linear flow of words. In writing there is only the linear flow of words, so this must be exploited to the full, and the choice of the right syntactic construction becomes essential. In sum, fewer textual linking obligatory XVS structures are found in speech, and obligatory XVS structures triggered by deictic adverbs such as here, there, now, and then function are used instead.

\section{The existence of the obligatory construction}

Over the past few years, work in Construction Grammar (Fillmore et al. 1988; Goldberg 1995, 2006; Kay and Fillmore 1999, among others) has stressed the role of constructions in structuring grammar. A central thesis of Construction Grammar is that information is not only conveyed through individual lexical items, but also through constructions, namely form-meaning correspondences or symbolic packages which in themselves carry meaning, independently of the 
words in the sentence. A construction is defined, within this framework, as a set of formal conditions on morphosyntax, semantic interpretation, pragmatic function, and phonology, that jointly characterize certain classes of linguistic objects. Particular semantic structures together with their associated formal expressions are therefore recognised as representational units: the ditransitive construction, the caused motion construction, the resultative construction, the intransitive motion construction, the passive construction, among others.

According to Goldberg (1995), a distinct construction is said to exist if one or more of its properties are not strictly predictable from knowledge of other constructions existing in the language. The different obligatory XVS types discussed in Section 3 seem to be clear examples of constructions in Goldberg's sense: that is, they are instances of distinct constructions whose meaning and/or form is not compositionally derived from other constructions existing in the grammar. They can be considered "unique constructions" in English and they must be "listed" as a closed set (Goldberg 1995), since they are not strictly predictable from other aspects of the grammar and carry a particular meaning which can only be conveyed through them when the whole structure is used. For instance, as already noted (cf. Section 3), the inversion pattern in an obligatory XVS triggered by preverbal so expresses a parallelism, lacks an equivalent with canonical word-order, and can be only paraphrased with subject-verb order plus additive too. Similarly, the negative parallelism conveyed in an obligatory XVS structure triggered by neither or nor can merely be paraphrased with alternative SVX word-order plus either because the meaning is constructional. Constructions such as these may therefore be seen as primitive units of grammatical organisation. They form a system of form-meaning pairs, that is, symbolic units in cognitivist terms (Langacker 1987: Ch. 2), which make up one layer of the mental representations of grammatical knowledge.

Goldberg and Jackendoff (2004: 532-533) illustrate three useful ways in which the recognition of constructions or symbolic units is possible:

(i) Constructions have unusual syntax and/or bits of specified morphology, as illustrated in (20) and (21) below.

20) Their reception, their critical transformation of new ideas, let alone their own discoveries, remain unknown and forcibly localized. ("Let alone" construction, Fillmore et al. 1988).

21) In any context in which the premises are acceptable, so is the conclusion. ("So is the conclusion"; so + be + NP construction). 
(ii) Constructions have some special meaning attached that brings about special restrictions, as shown in (22) where the meaning is presentative (cf. Section 5).

22) Oh, she must have finished, here is the patient now. (restriction: the verb must be intransitive)

(iii) Constructions contain a special element that signals the construction, and occupies a standard syntactic position, as can be seen in (23) where the enumerative listing conjunct triggers the XVS construction.

23) Third was the steel eight-foot fence at the edge of the paved playground of the school they had all attended until June and would attend again in September. (sequential-construction).

The obligatory XVS types discussed in Section 3 fall into one or other of these subtypes and, in each case, some special interpretation is associated with the syntactic structure. All the inversions share an underlying schema of the form XVS, where $\mathrm{X}$ obligatorily triggers the construction which, as will be shown, is not a mere stylistic variant of its canonical counterpart. Syntactically, for instance, the preverbal constituent is restricted to adverbial phrases - which in themselves are restricted on semantic grounds (cf. Section 5) - and their postverbal placement makes the sentence ungrammatical or different in meaning. In (24a) for instance, preverbal here has two functions: firstly, it designates the trajectory, that is, the location of the addressor and secondly, it designates David McNeil's location as being close to the addressor. In (24b), by contrast, here simply designates the location of the addressor. This is why the XVS construction can occur with locative adverbs that do not refer to the location of the addressor (cf. 24c), whereas the canonical SVX version cannot (cf. 24d). In (24d), the deictic adverb here is at the location of the speaker, which is inconsistent with across the street.

24) a. Here comes David McNeil.

b. David McNeil comes here.

c. Here comes David McNeil across the street.

d. * David McNeil comes here across the street.

e. David McNeil comes here occasionally.

f. * Here comes David McNeil occasionally.

The verb also works differently in the XVS and SVX versions. In (24a), comes makes reference to the time the sentence is uttered: the instant David McNeil arrives. This is not the case in (24b), where the present tense form has a more generic meaning and time reference does not necessarily need to be instantaneous. This is why the SVX version in (24e), but not the XVS version in (24f), 
can occur with modifiers (i.e. occasionally, regularly, frequently, habitually, etc.) which are restricted to generic, not instantaneous, time reference. ${ }^{4}$

Correlating with these semantic differences are major syntactic and phonological differences between the obligatory XVS structures and their canonical counterparts. For instance, obligatory XVS structures are syntactically constrained (Chen 2003: 3) in that they cannot be negated (cf. 25a), whereas the non-inverted construction can be negated (cf. 25b). Similarly, the verb in obligatory XVS structures cannot be transitive (26a) whereas the SVX version allows for transitive verbs (26b). Finally, the preverbal constituent in obligatory XVS structures needs to be stressed as in (27) which features a preverbal accented there (Birner, 1996: 25). As illustrated in (28), there are also examples where preverbal there is not stressed but these are examples of the so-called existential-there construction rather than examples of an obligatory XVS structure. In (27), locative there is a demonstrative adverb contrasting with here which performs a deictic referential function and could be replaced by a demonstrative. In (28), by contrast, existential-there is a function word, whose locative meaning has been largely bleached. It has been has been reanalysed as a pronoun and no longer conveys deictic reference.

25) a. * Here is not the patient now.

b. The patient is not here now.

26) a. * Here wrote David McNeil.

b. David McNeil wrote here.

27) He looked below the desk and THERE were the notes for his X-ray request.

28) There will be two more weeks of school.

It seems clear that the obligatory XVS structures discussed so far have syntactic, semantic, pragmatic and phonological properties that are markedly different from the corresponding SVX word-order. From this it follows that obligatory XVS structures are not mere stylistic variations of the simple sentences but are, rather, constructions - pairings of form and meaning — where semantic conditions are associated with syntactic conditions.

$4 \quad$ As an anonymous reviewer aptly notes, the specific time reference of the XVS version in (24a) also reflects the historical background, where inverted structures were particularly associated with narrative (cohesion), so concrete events in time or concrete argumentation (as they still are in other Germanic languages): see Carroll \& Stutterheim (2002), among others. It is remarkable, then, that the few relics of inverted word order that still survive today, seem to preserve this prototypical function of XVS to some extent. This, as the reviewer notes, is not unlike other constructions that are on the brink of extinction, for instance the decline of weorðan in Old English (Petré 2010). 
Constructions are idiomatic or fixed not only because there is no comparable word-order variant or because this conveys a different meaning, but also because they specify a pragmatic or semantic meaning that is distinct from what might be calculated from the associated semantics of the set of items that make up the whole syntactic template. For example, the $S o+b e+N P$ construction in (21) means, informally, 'if the premises are acceptable, then the NP, namely the conclusion, is also acceptable'. The XVS construction expresses a parallelism between both clauses. In other words, it performs a connective function and at the same time allows the introduction of new information, i.e. the postposed subject, in discourse. The construction semantics cannot be fully predicted on the basis of the constituent parts of the construction. Rather, as Lakoff (1987: 474) notes, what we have here is "a speech act construction, which is specified as part of the grammar of English and is restricted in its use to expressing a precise illocutionary force" (parallelism with the preceding clause).

Construction Grammar does not only recognise constructions as theoretical entities, but also views grammar as being essentially made up of a very large set of constructions that form an interconnected, structured system or network. One of the main features of this network is that its components differ from one another but are also related to one another through different forms of inheritance (Goldberg 1995: 72 ff.). Inheritance allows one to capture the fact that two constructions may be in some ways distinct but in other ways similar. This is why two parent constructions with partially conflicting specifications contribute to a daughter construction in such a way that the latter may display selective features of the former in what is to be regarded as a novel and unique structural creation. In fact, recent research (Chen 2003, among others) has shown that whole syntactic templates may have prototypical structure in that they are grouped in relation to a unit in the schematic network which is naturally most salient - the prototype - and form with it a family of nodes - extensions from the prototype - in the system. In what follows, I will show that, despite their formal and functional dissimilarities, the obligatory XVS types studied in this research (cf. Section 3) still relate to one another in systematic and predictable ways, and that the notion of inheritance links referred to above may be the best way to capture the structure of these constructions. It will be demonstrated that all the constructions relate to one another through the prototype construction by virtue of the fact that they all share something with it, like the lexical item there in Lakoff's celebrated example of a radial category, or the subject-auxiliary inversion schema in Goldberg (2006); see Taylor 1995: 116 ff.; Croft \& Cruse 2004: 272 ff.).

Goldberg's (2006: 166-182) constructional analysis of subject-auxiliary inversions, for instance, includes yes/no questions, (non-subject) wh-questions, counterfactual conditionals, initial negative adverbs, wishes/curses, exclamatives, comparatives, negative conjuncts, and positive rejoinders. She shows that 
there exists a systematic difference in form (subject-auxiliary inversion), which signals a systematic difference in function (a distinction from prototypical, positive sentences). This leads her to argue that the constructions exhibiting subjectauxiliary inversions naturally form a coherent functional category that has conventionalized extensions radiating out from a central core, as illustrated in Figure 1 , where the partial semantic overlap metonymically motivates the syntactic correspondences between the various inverted constructions. In other words, Goldberg reconstrues the category of subject-auxiliary inversions as a halo of constructions that stand in contrast to prototypical sentences. The systematic difference in form (subject-auxiliary inversion) signals a systematic difference in function (a distinction from prototypical sentences).

Figure 1. Functional category of SAI constructions with prototypical sentence as its prototype and markedness links motivating each of the extensions from the prototype (Goldberg 2006: 179)

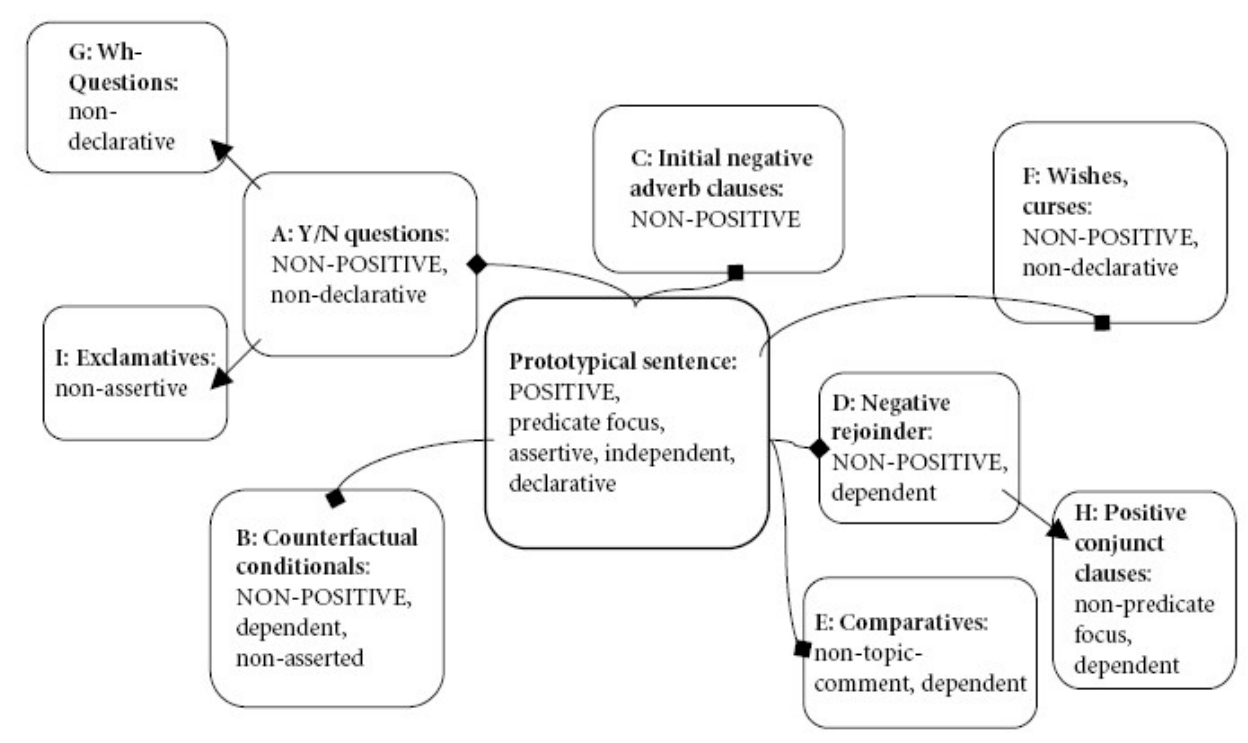

\section{A constructional analysis of obligatory XVS structures}

On the basis of the corpus-based analysis, the prototypical obligatory XVS construction in English is the presentative XVS construction. Three constructions extend from the prototype, as illustrated in Figure 2 on page 72: 
(i) the perceptual XVS construction

(ii) the sequential XVS construction

(iii) the anaphoric/additive XVS construction

The presentative XVS construction is represented in Figure 3 below, where DA codes the spatial or temporal deictic adverb, which triggers the inversion of the verb and the subject.

Figure 3. The presentative XVS construction [DA + VB + SUBJ $]$
\begin{tabular}{|l|l|c|}
\hline [DA + & \multicolumn{1}{|c|}{ VB } & + SUBJ $]$ \\
\hline Here & INTRANSITIVE VERB: \\
There & Copular be & NP \\
Now & Motion verb $($ go, come $)$ & \\
Then & Location verb (sit, stand, lie $)$ & \\
\hline
\end{tabular}

The corpus-based results showed that 362 of the 631 instances retrieved were examples of this construction which carries the implication that the subject, which represents new information, is presented for the first time and linked to the previous discourse by the preverbal placement of a spatial or temporal deictic. This type of obligatory XVS structure, which for some (Dubrig 1988) constitutes the "central deictic prototype", serves what previous work has claimed to be a cohesive and presentative function. Bolinger (1977: 93), for instance, regards the construction as "presenting something on the immediate stage" by bringing something literally before the addressee's presence. This claim is further elaborated by Dubrig (1988: 91) who claims that the construction encompasses a pragmatic presentative function, which consists of "directing the addressee's conscious attention to an object in his environment by making him focus on a region in his perceptual field". This is certainly the case when the preverbal deictic in the XVS structure performs exophoric reference (Halliday and Hasan 1976) and refers to a concrete time or space as illustrated in (29) and (30) below. For this reason, Green (1982: 130) argues that obligatory XVS structures triggered by here, there, now, and then are a typical "oral language construction", because its use seems to be subject to the restriction that there must be a perceptual field shared by both speaker and hearer and an interaction between both of them. However, the data retrieved from the corpora show that, though the presentative XVS construction is more frequent in speech, it is also attested in writing. This is so because the deictic reference conveyed through this XVS structure can also be made to the text itself. In other words, a text creates its own deictic dimensions and offers an alternative perceptual field which is available to the writer and the reader, and in which direct speech contexts with a conversational status may also be present. The presentative XVS construction is unique in that it designates both the spatial or temporal location of the ad- 
dressor while at the same time designating the location of the postposed subject as being close to the addressor. The preverbal deictic points to a spatial or temporal location and once the addressee's attention is directed towards that location, he can focus 'more easily' on the postposed subject, which introduces the new information and receives prominence in discourse, as illustrated in (31). In this example, the addressor is not only asserting that Fanny Allen is arriving, but is also directing the attention of the addressee to the location specified by here. Since there is no truth-conditional SVX alternative, it can be said that the presentative function in this type of XVS structure has been lexicalised in Present-day English. Such a process of lexicalisation fixes the construction as a distinct unit (Brinton \& Traugott 2005, Traugott \& Trousdale 2013).

29) We have been waiting for too long but here comes the bus.

30) Because Lincoln Hall was built in the 1960s, Jardine said: "now is the appropriate time to make significant changes".

31) At the window Jenny peered over the curtain: "And here is Fanny Allen, decked out like a Christmas tree, skirt half up her backside".

32) a. Here are the water samples and results.

b. There are the water samples and results.

The preverbal constituent that triggers the presentative XVS construction is restricted on syntactic and semantics grounds: it must be an adverb phrase which conveys spatial (e.g. here, there), or temporal (e.g. now, then) deictic reference. As illustrated in (32) above, here and there differ in that they show the location as more or less proximate from the point of view of the addressor, after which the new information represented by the postverbal subject is introduced. Langacker (1999: 45) points out that "the existence of a landmark presupposes the existence of a trajector". This is certainly true in the presentative XVS construction: the preverbal placement of the deictic element presupposes the introduction of new information in postverbal position. This is why the verb cannot be negated in this construction (cf. 33). In (33a), the deictic points to the location of the addressor which is a starting point for the location of the trajector, i.e. the subject. To negate the verb would be to deny the existence of the subject (cf. 33b). It would therefore be meaningless to present a location if the existence of the figure or trajector to be presented around that location is denied. 
Figure 2. A radial category of obligatory XVS syntactic structures. For reasons of clarity only a few shared links are shown

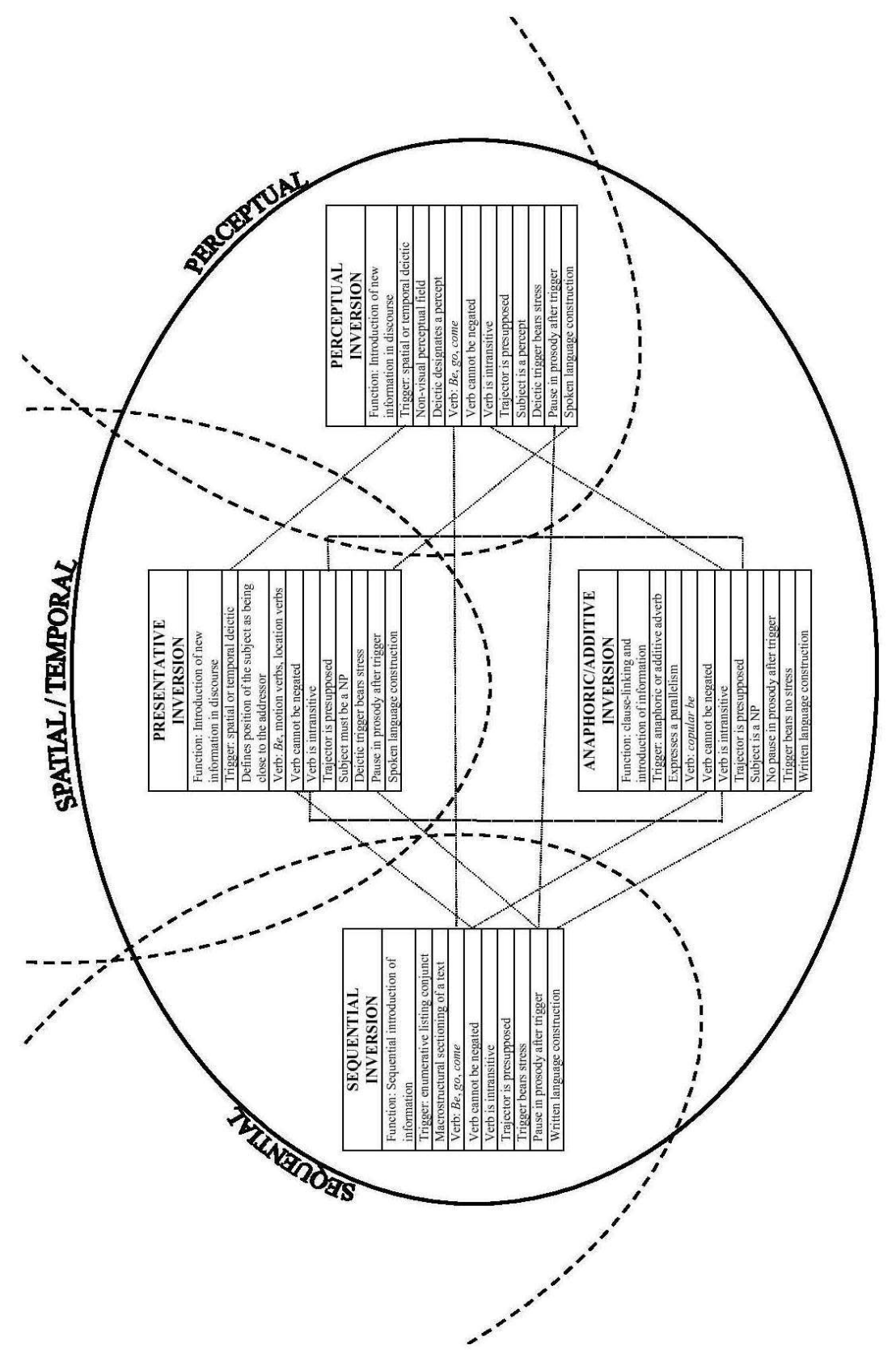


33) a. Here is our media correspondent Toring Douglas.

b. *Here is not our media correspondent Toring Douglas.

c. Our media correspondent Toring Douglas is/writes/swims here.

The verb in the presentative XVS construction is also syntactically and semantically restricted. The construction only allows intransitive verbs. The most common verb is copular be (cf. 33) - which is the most general lexical item that expresses a predicate of location - and some basic-level verbs of location, namely lie, stand and sit, though verbs of motion such as go and came (cf. 34) may also occur. The restriction to these types of verbs is not surprising, since the function of the construction is to present new information in discourse by moving the attention of the addressee towards the location specified by the preverbal constituent which in turn is defined in relation to the proximity of the addressor (cf. 3436). This is not the case in an SVX word-order where, though the deictic specifies a temporal or spatial location, it does not define the location as proximate from the point of view of the speaker and both transitive and intransitive verbs can be used (cf. 33c). In its most prototypical sense, the predication in the presentative $\mathrm{XVS}$ construction is simultaneous with the speech act and is in the present tense (cf. 34 and 35), though past tenses are also used, as seen in (36).

\section{4) Here stands Clouston.}

35) There comes Jesus Christ.

36) Here was bloody Saskia.

In the presentative XVS construction the postposed subject, which is put into focus, can be a physical or abstract entity (36 and 37) but it is constrained in that it can only be represented by a noun phrase. Examples where the subject function is represented by a pronoun cannot be inverted in English (Quirk et al., 1985: 881), as shown in (38).

37) Here is a major dilemma.

38) a. *Here is he.

b. Here he is.

From a phonological perspective the deictic triggers in the presentative XVS constructions bear stress, since their preverbal placement is highly marked in English. Stress of the preverbal deictic is a result of the function performed by the presentative XVS construction: the deictic must be stressed since the ad- 
dressor's intention is first to draw the addressee's attention towards a location in order to allow him to better interpret the new information, the subject, which is placed in postverbal position (cf. 39a). Further, the stress of the deictic is accompanied by a pause in prosody (marked with a slash in the example). Such a pause indicates a boundary in discourse and the process can be represented as follows: first the deictic - i.e. the location of the addressor - is emphasised, then time is given to the addressee to realise it (pause), and only afterwards is the new information presented in discourse and anchored to the location specified by the deictic. Both the stress and the pause in prosody are required in the XVS construction (39a) but not in the SVX version where the deictic remains in an unmarked position (39b).

39) a. THERE / lie the reasons for Clinton's confidence.

b. The reasons for Clinton's confidence lie there.

The first extension from the prototype is the perceptual XVS construction, which is represented as in Figure 4 below:

Figure 4. The perceptual XVS construction [DA + VB + SUBJ]

\begin{tabular}{|l|c|c|}
\hline [DA + & VB & + SUBJ $]$ \\
\hline Here & & \\
There & & NP is a \\
Now & Verbs: be, come, or go & precept \\
Then & & \\
& & \\
\hline
\end{tabular}

The corpus-based results showed that 134 of the 631 instances retrieved were examples of this construction, which inherits from the prototype different parameters of form and meaning. The perceptual XVS construction also performs a presentative function in that it allows for the presentation of the new information, represented by the postposed the subject, for the first time in discourse, thus conforming to the principle of Communicative Dynamism, cf. (40)-(41). As in the presentative XVS construction, the new information is anchored to the preceding discourse by the preverbal placement of a deictic which triggers the construction. However, in the perceptual XVS construction the deictic makes reference to a percept - sound, taste, smell, pain, emotion etc. — in the addressor's nonvisual perceptual field and not to a spatial or temporal location, as illustrated in (42a) below. The perceptual construction thus inherits from the prototype a metaphorical mapping of physical or temporal space onto perceptual space. In (41a), for 
instance, here refers to a perceptual rather than a spatial location. The SVX wordorder in (42b) cannot be felicitously used in this way because the postverbal deictic performs a spatial reference and represents a physical location.

40) Here goes the buzz.

41) And here is the pinch.

42) a. Here comes the knocking.

b. *Here does not come the knocking come.

As illustrated above, cf. (40)-(42), in perceptual XVS construction the postposed subject is constrained in that it must be represented by a percept. However, postposed subjects represented by physical entities, which give rise to percepts, may also occur in this construction (cf. 43). In such cases there is a conceptual metonymy by which the physical entity stands for the percept, as illustrated in (43). As was the case in the prototype, the preverbal placement of the deictic element in the perceptual XVS construction presupposes the introduction of the subject, i.e. the new information in discourse, in postverbal position (cf. 42a), and the verb cannot be negated (cf. $42 \mathrm{~b}$ ).

43) Here goes the alarm clock (alarm clock = buzz)

44) *Now rings the bell.

The verb is also constrained in that it cannot be transitive (44) and is restricted to copular be, go and come. In the case of go and come there is a conceptual metaphor by which the verbs are used to indicate activation rather than motion. In (42a), for instance, come does not indicate physical movement but activation of the knocking sound. The verb in the predicative XVS construction is normally in the present tense (cf. 42). Time reference, however, is also expressed in the deictic adverb. There, then, refers to a location in non-visual perceptual space at a time that is either present or in the recent past (cf. 45). Here, by contrast, refers to a location in nonvisual perceptual space at a time that is in the future (cf. 46). In (45), for instance, it is implied that the bell has just rung, whereas example (46), by contrast, can be used in a context in which the bell has not yet rung but the addressor knows - perhaps by looking at the clock two seconds before the bell rings - that it will do so very soon.

45) THERE is the bell.

46) And here is the bell. 
The second extension from the prototype is the sequential XVS construction, represented in Figure 5. ELC codes the enumerative listing conjunct which triggers the inversion of the verb and the subject.

Figure 5. The sequential XVS construction [ELC + VB + SUBJ $]$
\begin{tabular}{|l|c|c|}
\hline$[$ ELC + & VB & + SUBJ $]$ \\
\hline First & & \\
Second & & NP \\
Third & Verbs: be, come, or go & \\
Finally & & \\
Etc. & & \\
\hline
\end{tabular}

The corpus-based results showed that 77 of the 631 instances retrieved were examples of this construction. The construction occurs when the preverbal deictic constituent in the presentative XVS construction is replaced by an enumerative listing conjunct (cf. Quirk et al. 1985: 635; see also Biber et al. 1999: 875), which includes ordinal triggers such as first, second, third, etc., and adverbs such as finally or lastly. As was the case with the prototypical presentative XVS construction, sequential XVS constructions allow the presentation of new information in clause-final position. The new information is linked to previous discourse by the preverbal placement of a temporal deictic (cf. 47). The deictic points to a temporal location and once the addressee's awareness is guided towards the location, the postposed subject, which represents new information, is introduced in discourse. Sequential XVS structures are unique in that in addition to their presentative function they allow the enumeration of pieces of information in an order chosen by the addressor, and perform a linking function, as illustrated in (48) below. Here the XVS constructions allow the addressor to give a temporally structured explanation of the topic. The XVS constructions in (48) differ in meaning from their canonical SVX counterparts. In this example, the preverbal constituents of the XVS constructions, namely first, second, and finally, function as adverbial pointers which help to indicate the progression of events and mark the successive stages in discourse. This would not occur in SVX word-order, where first, second, and finally would no longer occupy a preverbal position, and would simply convey a temporal meaning affecting the verb, without performing a cohesive function. Thus, the sequential XVS constructions explicitly signal the links between ideas and the connections between passages in the text. In other words, they are unique constructions in signalling the macrostructual sectioning of a text, and create textual cohesion. As I have argued elsewhere (Prado-Alonso et al. 2010), and on the basis of the corpusbased analysis, these types of structures are most frequently attested in the writ- 
ten mode, especially in academic prose, where it is commonly used in the development of arguments, and allows the addressor to give a detailed, concise and temporally structured explanation. Sequential XVS structures mark the links between ideas overtly and help the addressee to understand better the sequence of facts, since he or she is guided temporally in each step of the discussion, and can easily note the most important statements of the message.

47) First came Peter, then came John.

48) Because relevant statistics are few, we divide gay-bashing incidents into three types based on the age of the victim. First are serious physical assaults and homicides committed against adult lesbians and gay males such as those reported in the House Criminal Justice Subcommittee hearings on Anti-Gay Violence (...) Second are assaults and related harassments of lesbian and gay male adolescents by their peers, such as those that gave rise to the Harvey Milk School in New York City for homosexual adolescents. The existence of such a school implies that mistreatment of homosexual adolescents is pervasive in the adolescent world. Finally, probably far more common than either of the other forms of assault and harassment are the beatings of effeminate boys.

As in the prototype, in the sequential XVS construction, the preverbal constituent presupposes the introduction of a postverbal subject which in turn means that the intransitive verb -be, go or come- cannot be negated because that would imply the non-existence of the subject. The preverbal constituent is also constrained in that it makes temporal reference to the text itself. In other words, the preposed constituent performs endophoric reference and temporally locates the postposed subject in the speech event, thus performing a cohesive function (cf. 48). It is in this sense that the sequential XVS construction extends temporally from the prototype and is a construction which belongs to "the speaker's organisation of his discourse" (Halliday and Hasan 1976: 239) explicitly signalling the connections between passages in a text.

Phonologically speaking, the triggers in sequential XVS constructions also bear stress and are followed by a pause in prosody. This is a result of the function performed by the construction which is used by the addressor to indicate a sequence of events in a particular time progression. The addressee's awareness is therefore firstly guided towards a particular temporal stage in the discourse context, which is phonologically emphasised, and then the new event or information is introduced. Neither the stress nor the pause in prosody are required in the SVX version, where the enumerative listing conjunct is not placed in an unmarked position. 
Finally, the third extension from the prototype is the anaphoric/additive XVS construction (58 of the 631 XVS instances retrieved from the corpora). As represented in Figure 6, this XVS construction extends from the prototype when the clause-initial deictic constituent is replaced by as anaphoric or additive adverbs such as so, neither, or nor, as shown in (49)-(51) below.

Figure 6. The anaphoric/additive XVS construction [ADD + VB + SUBJ]

\begin{tabular}{|l|c|c|}
\hline [ADD+ & VB & + SUBJ] \\
\hline So & & \\
Neither & Verbs: copular be & NP \\
Nor & & \\
& & \\
\hline
\end{tabular}

In this construction, the initial additive or anaphoric adverb stands for given information, and has a cohesive effect, cf. (49)-(51). As the prototype, the anaphoric/additive XVS construction allows the introduction of new information, which is placed in clause-final position (the subject), and links it to the previous discourse by the clause-initial placement of given information. However, the anaphoric/additive XVS construction differs from the prototypical presentative XVS construction in that it does not express relations from within the scene; that is, it does not make use of a preverbal locative constituent. Rather, the construction is useful for signalling connections between specific information in the development of the addressor's argument. It is unique not only in that there is no completely equivalent canonical word-order (it can only be paraphrased with subject-verb order plus additive too, or, or either) but also in that it puts the subject into focus and emphasises the parallelism between the inverted clause and the preceding clauses or discourse. In other words, the preverbal trigger in this extension refers back to an entire predication and attributes to (so) or excludes another referent (neither/nor) from the same predication, as shown in (49)-(52).

49) Conservative efforts in 1990 to temper the effects of the poll tax and to slow down the implementation of NHS reform are evidence for the robustness of the Downsian median. $\underline{\text { So }}$ are the strenuous efforts of Neil Kinnock to lead the Labour Party to it.

50) Major changes in either markets or policy are unlikely in the short run. Neither is any set of partial reforms likely to 'solve the poverty problem. 
51) I think what is not legitimate is either for us to seek by military force to overturn the government of Iraq though that may happen in the process nor is it legitimate for us to acquire and I underline the word acquire Iraqi territory.

52) Transoceanic commerce is one of these inter-relationships. The common heritage of science is another, $\underline{\text { so }}$ is the aspiration to add to it.

As the prototypical obligatory XVS construction, the anaphoric/additive XVS construction presupposes the introduction of new information, represented by the subject, in postverbal position, since the main function of the construction is the linking of information to the previous discourse. The verb, which is most commonly copular be, cannot be negated, but negation may be implied in the preverbal constituent and depends on the negative equivalence between the cotext and that preverbal constituent, as illustrated in (50)-(51).

According to Green (1982: 130), "inversion after pronominal so and neither (...) seems to be much more frequent in speech". However, the present corpusbased study has shown that this construction is more frequently attested in writing than in speech. This is so because the written mode generally needs more cohesive constructions such as anaphoric/additive XVS constructions than the spoken mode, since, as noted by Chafe (1992), production takes place most commonly under conditions of displacement, that is, it deals with events which are not part of the immediate environment of addressor and addressee. By contrast, the spoken language tends to have a more fragmented character and, due to matters of speed of production, exhibits a far less structured syntax than the written language (cf. Section 3). However, when anaphoric/additive XVS structures occur in speech (cf. 52), the preverbal constituent is unstressed and is not followed by a pause, since the construction simply performs a text-structuring function. In this sense, it differs from the prototype in which the preverbal locative constituent is stressed by the addressor in order to guide the addressee's attention towards a particular location and link the new information, placed in clause-final position, in relation to such a location.

\section{Summary and conclusions}

Obligatory XVS constructions specifically rearrange the order of the preverbal and postverbal constituents of sentences. The common denominator in this type of structures is that the subject appears in postverbal position. The movement of two major constituents in the clause, i.e. subject and verb, conveys a pragmatic and semantic effect which cannot be expressed with other constructions, such as passives, cleft-constructions, left-dislocations, etc. Since obligatory XVS con- 
structions manipulate the $\mathrm{X}$ and the $\mathrm{Y}$ in [X123Y] types of structures, they may be used because encoders want to pay special attention to the $\mathrm{X}$, to the $\mathrm{Y}$, or to both (Chen 2003; Kreyer 2006; Prado-Alonso 2008; Prado-Alonso et al. 2010).

Most functional studies on XVS constructions do not consider XVS structures which are syntactically and semantically fixed, since it is argued that there is no linguistic variation involved in the use of these constructions. The present study has shown, however, that restricting the analysis of XVS constructions to the non-obligatory type is unmotivated and that obligatory XVS constructions are also important constructions in structuring grammar. Through the detailed investigation of the syntax, phonology, semantics, and pragmatics of the different obligatory XVS types, it has been shown that in fact they are clear instances of constructions in Goldberg's (1995) sense. Obligatory XVS constructions are thus best understood as symbolic units, that is, pairings of form and meaning, in which all of its types share an underlying schema of the XVS forms, where X obligatorily triggers the constructions, the verb is intransitive, and in which the SVX word-order is grammatically unavailable or different in meaning.

Beyond this, the present analysis has also shown that obligatory XVS constructions can be seen as a radial category. The category is formed around a unit that is naturally most salient, i.e. the prototype (Rosch \& Mervis 1975), and extensions "categorising relationships involving some conflict in specification between the standard and the target" (Langacker 1991: 548) are added on the basis of resemblance to the prototype and form with a schematic network. On the basis of the corpus-based analysis, the prototypical form in English is the presentative XVS construction, whose function is to present new information in a temporal or spatial location which is defined in relation to the addressor and the postposed subject. Three extensions extend from the prototype - namely perceptual, sequential, and anaphoric/additive XVS constructions - which relate to one another because they all share features with the prototypical form and belong with it in a family of nodes. The network range goes from the temporal or spatial locative function of the presentative XVS construction to the perceptual locative meaning of perceptual XVS construction and the sequential and clause-linking function of sequential and anaphoric XVS constructions, and in all these functions categorisation is formally perceptible.

The form-meaning correspondence of the extensions derives in large part from the prototype. For instance, the perceptual XVS construction allows a metaphorical mapping of physical or temporal space onto perceptual space or a conceptual mapping by which the verbs go and come indicate activation. Similarly, sequential XVS constructions show a temporal extension which allows the ordering of the level of discourse sequentially. It is in this sense that the formmeaning correspondences of the extensions are highly motivated (Goldberg 1995: 69) and cluster around the prototypical obligatory XVS form. 


\section{REFERENCES}

Baker, Paul. 2009. Contemporary corpus linguistics. London: Continuum.

Barlow, Michael. 2000. Corpus of spoken professional American English. CD-ROM version. Houston, TX: Athelstan.

Biber, Douglas. 1988. Variation across speech and writing. Cambridge: Cambridge University Press.

Biber, Douglas, Stig Johansson, Geoffrey Leech, Susan Conrad \& Edward Finegan. 1999. The Longman grammar of spoken and written English. London: Longman.

Birner, Betty. 1996. The discourse function of inversion in English. New York: Garland.

Bolinger, Dwight. 1977. Meaning and form. London: Longman.

Bresnan, Joan \& Joni M. Kanerva. 1992. Locative inversion in Chichewa: A case study of factorization in grammar. In Tim Stowell \& Eric Wehrli (eds.), Syntax and semantics No. 26: Syntax and the lexicon, 53-101. New York: Academic Press,.

Brinton, Laurel J. \& Elizabeth Closs Traugott. 2005. Lexicalization and language change. Cambridge: Cambridge University Press.

Carroll, Mary \& Christiane von Stutterheim. 2002. Typology and information organisation: Perspective taking and language-specific effects in the construal of events. In Anna Giacalone Ramat (ed.), Typology and second language acquisition, 365-402. Berlin: Mouton de Gruyter.

Chafe, Wallace. L. 1992. Information flow in speaking and writing. In Pamela Downing, Susan D. Lima, \& Michael Noonan (eds.), The linguistics of literacy, 17-29. Amsterdam/Philadelphia: John Benjamins.

Chafe, Wallace L. 1994. Discourse, consciousness, and time: The flow and displacement of conscious experience in speaking and writing. Chicago: University of Chicago Press.

Chen, Rong. 2003. English inversion: A ground-before-figure construction. Berlin: Mouton de Gruyter.

Croft, William \& D. Alan Cruse. 2004. Cognitive linguistics. Cambridge: Cambridge University Press.

Dorgeloh, Heidrum. 1997. Inversion in Modern English: Form and function. Amsterdam: John Benjamins.

Dubrig, Hans Bernhard. 1988. On the discourse function of subject-verb inversion. In Joseph Klegraf \& Dietrich Nehls (eds.), Essays on the English language and applied linguistics on the occasion of Gerhard Nickel's 60th birthday, 83-95. Heidelberg: Julius Gross Verlag.

Fillmore, Charles. J. 1999. Inversion and constructional inheritance. In Andreas Kathol, JeanPierre Koenig \& Gert Webelhuth (eds.), Lexical and constructional aspects of linguistic explanation, 113-128. Stanford: Center for the Study of Language and Information Publications.

Fillmore, Charles J., Paul Kay \& Catherine O'Connor. 1988. Regularity and idiomaticity in grammatical constructions: The case of let alone. Language 64. 501-538.

Goldberg, Adele E. 1995. Constructions: A Construction Grammar approach to argument structure. Chicago: University of Chicago Press.

Goldberg, Adele. E. 2006. Constructions at work: The nature of generalization in language. Oxford: Oxford University Press.

Goldberg Adele E. \& Ray Jackendoff. 2004. The English resultative as a family of constructions. Language 80. 532-568. 
Green, Georgia M. 1982. Colloquial and literary uses of inversion. In Deborah Tannen (ed.), Spoken and written language: Exploring orality and literacy, 119-154. Norwood, NJ: Ablex.

Halliday, Michael A. K. \& Ruqaiya Hasan. 1976. Cohesion in English. London: Longman.

Hartvigson, Hans \& Leif K. Jakobsen. 1974. Inversion in Present-day English. Odense: Odense University Press.

Hofland, Knut, Anne Lindebjerg \& Jørg Thunestvedt. 1999. ICAME collection of English language corpora. 2nd edition, CD-ROM version. Bergen: The HIT Centre.

Huddleston, Ronald \& Geoffrey K. Pullum 2002. The Cambridge grammar of the English language. Cambridge: Cambridge University Press.

Kay, Paul \& Charles J. Fillmore. 1999. Grammatical constructions and linguistic generalizations: The What's $X$ doing $Y$ ? construction. Language 75. 1-33.

Kreyer, Rolf. 2006. Inversion in modern written English: Syntactic complexity, information status and the creative writer. Tübingen: Gunter Narr.

Lakoff, George. 1987. Women, fire, and dangerous things: What categories reveal about the mind. Chicago: University of Chicago.

Langacker, Ronald. 1987. Foundations of cognitive grammar. Vol. 1: Theoretical prerequisites. Stanford: Stanford University Press.

Langacker, Ronald. 1991. Foundations of cognitive grammar. Vol. 2: Descriptive application. Stanford: Stanford University Press.

Langacker, Ronald. 1999. Assessing the cognitive linguistic enterprise. In Theo Janssen \& Gisela Redeker (eds.), Cognitive linguistics: Foundations, scope, and methodology, 13-59. Berlin/New York: Mouton de Gruyter.

Nelson, Gerald. 1988. The International Corpus of English. The British component. Survey of English Usage: University College London.

Petré, Peter. 2010. The functions of weorðan and its loss in the past tense in Old and Middle English. English Language and Linguistics 14.3. 457-484.

Prado-Alonso, Carlos. 2008. The iconic function of full inversion in English. In Klaas Willems \& Ludovic De Cuypere (eds.), Naturalness and iconicity in language, 149-166. Amsterdam: John Benjamins.

Prado-Alonso, Carlos. 2011. Full-verb inversion in written and spoken English. (Linguistics Insights Series: Studies in Language and Communication 127.) Bern: Peter Lang.

Prado-Alonso, Carlos \& Juan Carlos Acuña-Fariña. 2010. A comprehensive account of full-verb inversion in English. Folia Linguistica 44.2. 509-553.

Quirk, Randolph, Sidney Greenbaum, Geoffrey Leech \& Jan Svartvik. 1985. A comprehensive grammar of the English language. London: Longman.

Rosch, Eleanor \& Catlin B. Mervis. 1975. Family resemblances: Studies in the internal structures of categories. Cognitive Psychology 7. 573-605.

Taylor, John R. 1995. Linguistic categorization: Prototypes in linguistic theory. Oxford: Clarendon Press.

Traugott, Elizabeth Closs \& Graeme Trousdale. 2013. Constructionalization and constructional changes. Oxford: Oxford University Press.

Schachter, Paul. 1992. Comments on Bresnan and Kanerva's "Locative inversion in Chichewa: A case study of factorization in grammar". In Tim Stowell \& Eric Wehrli (eds.), Syntax and semantics No. 26: Syntax and the lexicon, 103-110. New York: Academic Press.

Webelhuth, Gert. 2011. Motivating non-canonicality in Construction Grammar: The case of locative inversion. Cognitive Linguistics 22.1. 81-105. 